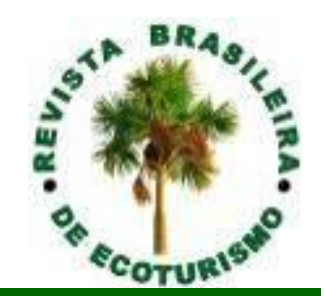

\title{
Impactos da política de turismo no município de Parnaíba (PI): percepção de diferentes sujeitos locais
}

\author{
Impacts of tourism policy in the city of Parnaíba (PI, Brazil): \\ perception of different subject sites
}

Andreia Magalhães da Rocha, Wilker Ricardo de Mendonça Nóbrega,
Mozart Fazito Rezende Filho

RESUMO: O presente estudo teve como objetivo analisar como são percebidos os impactos da política de turismo no município de Parnaíba-PI a partir da visão de diferentes sujeitos que atuam no setor. A metodologia da pesquisa é do tipo bibliográfica, documental e de campo, sendo de abordagem qualitativa, natureza exploratória e análise de dados descritiva, tratando-se de um estudo de caso. Os sujeitos abordados na pesquisa foram: residentes da zona urbana de Parnaíba-PI, equipe da Superintendência Municipal de Turismo e membros do Conselho Municipal de Turismo. O recorte temporal da análise está compreendido entre os anos de 2010 a 2016, período em que foram efetivadas ações do Programa de Desenvolvimento do Turismo no Nordeste- PRODETUR/NE, Programa de Aceleração do Crescimento- PAC, Contratos de Repasse do MTUR e Programa Nacional de Acesso ao Ensino Técnico e Emprego- PRONATEC. O estudo apontou que não se pode afirmar que a população local estava inserida efetivamente nas ações públicas de turismo em Parnaíba. Os investimentos foram oportunos para o contexto, sendo classificados pelos residentes como benéficos, ou seja, entendem que é um componente entre os demais necessários ao desenvolvimento do turismo local. No entanto, a predominância do discurso e da prática turística em relação à população continua sendo operacional, com investimentos pontuais, não sendo capaz de transformar a dinâmica do turismo local numa perspectiva do desenvolvimento local.

PALAVRAS-CHAVE: Turismo; Políticas Públicas; População Local; Parnaíba-PI. 


\section{ABSTRACT}

The main objective of this present study is to analyze how the population has been inserted in the conception and implementation of the actions undertaken by the tourism public management in Parnaíba-PI. The methodology used in the analysis consists of a qualitative approach and an exploratory investigation. For that, besides the bibliographical and documentary research, it was developed a field research with the residents of Parnaíba, superintendent and the team of the Municipal Superintendence of Tourism and members of the Municipal Council of Tourism. The temporary clipping of analysis is among years 2010 to 2016, period which actions were effective of the Program of Development of Tourism in the Northeast-PRODETUR/NE, Growth Acceleration Program- PAC, Contracts of Transfer of the Ministry of Tourism and National Program of Access to Technical Education and Employment-PRONATEC. As conclusive aspects, the study points out that it cannot be affirmed that the local population is effectively inserted in the specific tourism public actions in Parnaíba. The investments were appropriate for the context, being classified by residents as beneficial, understand that is one component among the other necessary for the development of local tourism. However, the predominance of the discourse and practice of tourism in relation to population remains to be continued operational, with specific investments, not being able to transform the dynamics of local tourism from a perspective local development.

KEYWORDS: Tourism; Public Policy; Local Population; Parnaíba-PI.

\section{Introdução}

A década de 1990 marcou o fortalecimento do turismo nas políticas de desenvolvimento nacional. O turismo emergiu como estratégia para 0 desenvolvimento das localidades, dada sua capacidade de geração de emprego e renda (BENI, 2006; DIAS, 2005; ENDRES, 2012; PIMENTEL; PIMENTEL, 2011). Desde então, o incentivo governamental que deu prioridade ao turismo tem modificado a realidade das localidades onde se desenvolve, impactando principalmente sua estrutura de produção e emprego (FRATUCCI, 2008).

O foco nos municípios, que caracterizava a Política Nacional de Turismo, evoluiu para o processo de regionalização ${ }^{1}$ após a criação do Ministério do Turismo, em 2003. Essa nova política priorizou ainda mais o turismo como elemento central de desenvolvimento, e reforçou a necessidade de participação efetiva dos órgãos e agentes públicos e privados, municipais e estaduais, além da sociedade civil organizada e outros envolvidos. Essa proposição da adoção de cooperação por parte do órgão nacional pode ter fortalecido a elaboração de políticas públicas específicas de turismo no país, além de reforçar a necessidade do envolvimento da população local no planejamento e desenvolvimento do setor.

O Programa de Regionalização do Turismo do Ministério do Turismo (MTUR) selecionou polos indutores de turismo em todos os estados da Unidade Federativa brasileira, para priorização de investimentos e incentivos públicos. Nesse contexto, esta pesquisa, engloba a região prioritária do 
turismo no Estado do Piauí, inserida na Região Turística Polo Costa do Delta, região Norte do Estado (Figura 1).

Figura 1: Localização do Município de Parnaíba.

Figure 1: Location of the Municipality of Parnaíba.

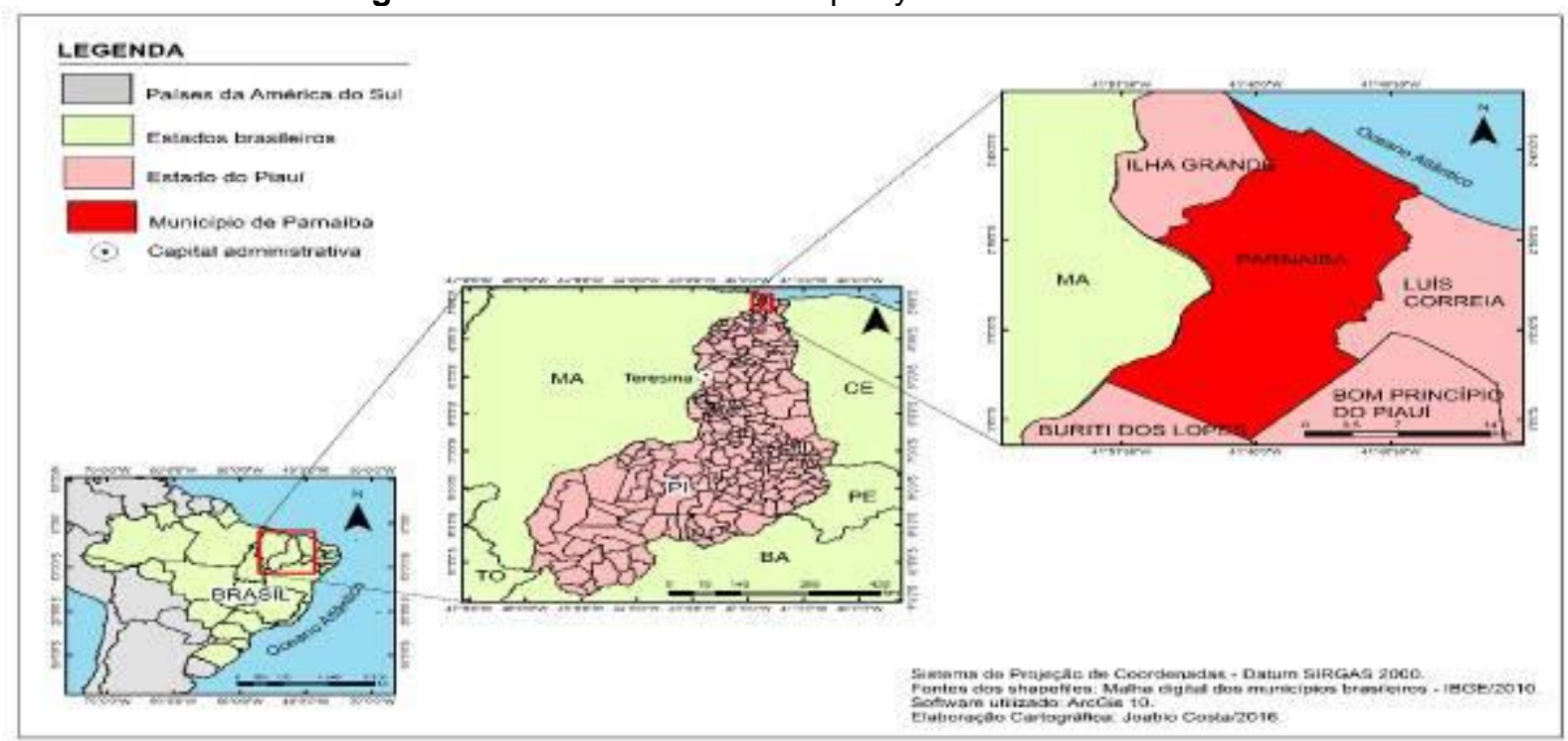

Fonte: Costa, (2016). Source: Costa (2016).

Para tanto, tem-se como objetivo geral analisar como são percebidos os impactos da política de turismo no município de Parnaíba-PI a partir da visão de diferentes sujeitos que atuam no setor. $O$ estudo também se utilizou de algumas indagações: Qual foi a natureza das principais intervenções turísticas realizadas no município que interferiram diretamente a população local no período em análise? Qual a repercussão das principais ações na localidade?

Nesse sentido, a investigação analisa se há compatibilidade entre 0 discurso oficial e a prática, no que se refere ao envolvimento da população nas principais ações desenvolvidas para o turismo local. $O$ estudo fornece elementos que podem contribuir para a gestão pública local, fazendo com que se torne mais efetiva. Dito de outra forma, a discussão aqui apresentada pretende contribuir para a análise das políticas de turismo a partir do contexto empírico contemplado na investigação localizado no Nordeste brasileiro, o Polo Turístico Costa do Delta/PI, tendo em vista a carência de publicações que abordam integralmente o tema, que observam apenas correlações parciais.

A pesquisa foi desenvolvida na zona urbana de Parnaíba (Figura 2); população: 137.485 habitantes; Renda média mensal: $R \$ 479,58$; Habitação: água encanada $(93,80 \%)$, energia elétrica $(98,79 \%)$ e coleta de lixo $(88,22 \%)$; População economicamente ativa ocupada (61\%), Índice de Desenvolvimento Humano Municipal-IDHM de 0,687 e crescimento demográfico anual de $0,97 \%$. 
Figura 2: Bairros de Parnaíba considerados na pesquisa.

Figure 2: Parnaíba neighborhoods considered in the research.

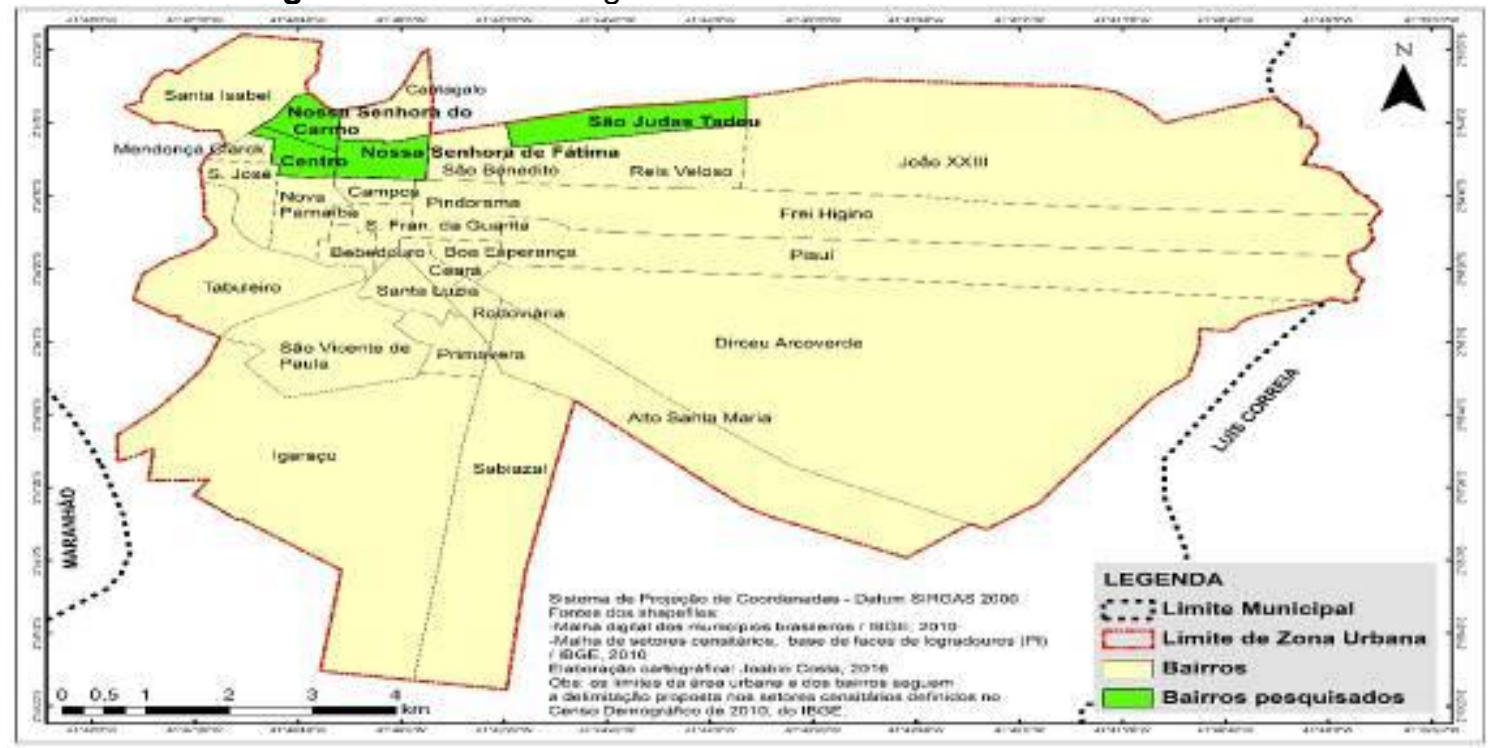

Fonte: Costa, (2016). Source: Costa (2016).

A área foi selecionada pela incidência dos investimentos turísticos realizados no município. O recorte temporal da análise está compreendido entre os anos de 2010 a 2016, período em que foram efetivadas ações do Programa de Desenvolvimento do Turismo no Nordeste - PRODETUR/NE, que compreenderam Estudos e Projetos, Saneamento Básico e demais investimentos turísticos derivados do Programa de Aceleração do Crescimento- PAC, Contratos de Repasse do MTUR e Programa Nacional de Acesso ao Ensino Técnico e Emprego - PRONATEC.

A fim de responder ao questionamento central da análise, foram adotados os seguintes procedimentos: pesquisa bibliográfica, documental e de campo, sendo de abordagem qualitativa, natureza exploratória e análise de dados descritiva. A estratégia de pesquisa adotada é a de um Estudo de Caso, pela centralidade em relação ao problema de pesquisa.

A pesquisa bibliográfica foi realizada em todas as etapas do processo investigativo (APPOLINÁRIO, 2004), em livros, dissertações, teses e artigos nacionais e internacionais, pesquisa documental em documentos municipais cedidos pela Superintendência de Turismo- SUPTUR e pesquisa de campo com aplicação de questionários de quinze perguntas abertas e fechadas a 81 residentes locais e de um roteiro estruturado contendo quatro perguntas abertas à Equipe da SUPTUR e ao Conselho Municipal de TurismoCOMTUR no período de 4 a 6 de julho de 2016.

Os critérios escolhidos para selecionar os participantes foram: proximidade e/ou tangência às intervenções aqui consideradas; tempo mínimo de residência de pelo menos 5 anos; e idade mínima de 23 anos, soma entre 18 anos de idade (maioridade civil) e residência mínima considerada para esta pesquisa.

É oportuno mencionar que também foi realizada uma entrevista com o Superintendente de Turismo; Coordenadora Geral de Projetos e Programas 
Turísticos e a Diretora de turismo da Superintendência de Turismo. Foram ainda entrevistados dois integrantes do Conselho Municipal de Turismo: representante do Curso de Turismo da Universidade Federal do Piauí- UFPI (membro 1) e representante da ONG Tartarugas do Delta (membro 2), responsáveis por propor e planejar ações para o desenvolvimento da atividade em nível municipal.

Em síntese, observa-se a que população local precisa ser considerada como um sujeito indispensável no planejamento e desenvolvimento da atividade turística, tendo em vista que os benefícios nas diferentes esferas devem ser o termômetro para alcançar indicadores positivos à população local em detrimento das consequências negativas próprias do setor turístico.

\section{Questões conceituais e relacionais sobre População Local e Turismo}

O turismo enquanto fenômeno social pode contribuir para 0 desenvolvimento das interações humanas, isto é, pode ser considerado uma prática que se materializa por meio dos agentes a ele associados (CARVALHO; GUZMÁN, 2011). Seu crescimento ao longo dos anos está diretamente relacionado com a ampliação da sociedade industrial. Dito de outra forma, a atividade acompanhou a evolução da sociedade, desde o surgimento do turismo moderno.

Entende-se que os fatores responsáveis por provocar o crescimento da atividade, especialmente nos países ocidentais, estão associados à política e à economia, sendo um dos setores econômicos com maior crescimento no mundo (AIRES; LORE, 2011; MCDOWALL; CHOI, 2010). Ademais, observase que outros aspectos influenciaram significativamente o fortalecimento da atividade historicamente, como os avanços tecnológicos, que favoreceram a dinâmica dos transportes e da comunicação, o reajuste da jornada de trabalho e a elevação da escolaridade. Todos esses elementos cooperaram sobremaneira para o aumento da motivação de pessoas para conhecer lugares diferentes.

Concomitantemente ao crescimento da atividade turística surge 0 aumento dos impactos derivados da sua prática (DALL'AGNOL, 2012). Entretanto, tal atividade continua sendo considerada uma oportunidade de melhoria de vida para os residentes locais (CAÑIZARES et al., 2014; CARDONA, 2015; CARNEIRO; EUSÉBIO, 2015; CHEN; CHEN, 2010; EUSÉBIO; RODRIGUES, 2014; FREDLINE; DEERY; JAGO, 2013; MENG; LI; UYSAL, 2010; NKEMNGU, 2015; OLIVEIRA, 2005). Há uma predominância de valorização do potencial econômico do turismo tanto na literatura quanto na prática, entretanto é crucial que se expanda o seu entendimento para que, de fato, a atividade possa contribuir para o desenvolvimento humano. De acordo com Aires et al. (2010, p. 41), "não se pode pensar no turismo sem pensar no contato pessoal e na relação entre os seres humanos". Neste contexto, entende-se que o potencial da atividade está menos concentrado na dimensão econômica, e mais nas dimensões social, ambiental e cultural, sem desconsiderar a primeira (FAZITO et al., 2017). 
No que se refere ao município em análise, percebe-se que os residentes convivem pacificamente com a prática do turismo e se organizam de maneiras diferenciadas para receber os visitantes, isto é, é um município que possui no turismo um recurso de estimada potencialidade, sendo 0 aspecto econômico um dos principais fatores percebidos pelos residentes. Contudo, Aires et al. (2010 p.24), destacam que "a importância do turismo se evidencia não apenas por sua contribuição econômica, mas, sobretudo, diante da promoção dos impactos causados na vida das pessoas e nos locais onde elas vivem".

Hall (2001, p.193), entende que "as decisões políticas refletirão o desejo de atender aos interesses da esfera pertinente do governo - nacional, estadual ou local - e não aos interesses de elementos da indústria do turismo definidos seccionalmente". Nesse contexto, é possível considerar que a política em suas diversas representatividades é imbuída de interesses que se fortalecem na medida em que encontra apoio e influência nas arenas e negociações existentes.

Logo, o aspecto humano torna-se um elemento necessário ao processo de desenvolvimento do fenômeno, uma vez que pode ser considerado um conceito complexo, refletindo uma divergência de interesses (FRATUCCI, 2008). Desse modo, o estudo das atitudes dos residentes torna-se importante para a gestão dos destinos turísticos, pois tende a agregar valor às deliberações desenvolvidas na localidade e permite uma melhoria na economia das regiões nas quais se expande, podendo produzir um efeito ambivalente em relação à percepção e à atitude daqueles (CARDONA, 2015; SANTOS; FERREIRA; COSTA, 2014).

Há uma variedade de nomenclaturas na literatura que se refere à população local (OLIVEIRA, 2005). No entanto, é necessário compreender que as abordagens estão relacionadas ao tipo de contexto em que a pesquisa é realizada, bem como à perspectiva de quem a desenvolve. Desse modo, têm-se os seguintes termos: comunidade local (CARVALHO, 2010), autóctones (BENI, 2006), residentes (ALVES et al., 2009), habitantes locais (SCÓTOLO; PANOSSO NETO, 2015), moradores locais (BALDISSERA; BAHL, 2012) e população residente (AIRES; PEQUENO; FORTES, 2010). Na linguagem política, a população local recebe uma outra nomenclatura, sendo denominada de sociedade civil. Esta se refere ao processo histórico vivenciado no Brasil e na América Latina, iniciado no final dos anos 1970, momento em que foi inserido no vocabulário político e passou a ser objeto de elaboração teórica (GOHN, 2004).

Esses impactos podem ser geralmente agrupados nas seguintes categorias: econômico; social, cultural e ambiental (CAÑIZARES et al., 2014; CARDONA, 2015; CHEN; CHEN, 2010; DÍAZ; LLURDÉS, 2013; EUSÉBIO; RODRIGUES, 2014; GORICA; KRIPA; ZENELAJ, 2012; LEE, 2013; MAZÓN, 2012; NKEMNGU, 2015; NUNKOO; RAMKISSOON, 2010; SANTOS et al., 2014; MARIA; VELASCO; SANTOS, 2016). Se as pessoas entendem que os benefícios são mais relevantes que os custos, o inverso também pode seguir a mesma lógica (GURSOY; KENDALL, 2006). 
Assim, os impactos ocasionados pela prática do turismo em um destino estão diretamente associados à forma como a atividade se apropria do espaço e de como as relações sociais e econômicas estão dispostas no contexto (CARVALHO; GUZMÁN, 2011). Estudos recentes sugerem que a população local que percebe um impacto positivo tem maior probabilidade de ser mais susceptível a apoiar seu desenvolvimento (RODRIGUES et al., 2014), bem como aqueles que possuem contato regular com os visitantes (ANDERECK; NYAUPANE, 2011).

\section{Políticas de turismo e população local em Parnaíba: compreensão da instância turística}

Constatou-se que no âmbito estadual a política pública é incipiente e inviabiliza uma maior orientação para o setor. Acredita-se que essa situação se reflete inclusive sob a inatividade do Conselho Estadual de turismo, comprometendo as reuniões regulares dos polos turísticos da região.

Em nível local, também foi verificado uma fragilidade da gestão ao que concerne à instituição da política pública de turismo. Constatou-se que as ações públicas estão concentradas basicamente em questões relacionadas a projetos de ordem executiva. Contudo, se diferencia da esfera estadual porque possui uma conjuntura potencialmente mais participativa.

O Plano Diretor do município considera o turismo como prioridade local, mas não há informações sobre a efetivação de planos e programas de desenvolvimento turístico municipal, embora haja a necessidade de fazê-lo.

A partir da análise dos documentos disponibilizados pela SUPTUR foi identificada a existência da Lei no 56 de setembro de 2014 que dispõe sobre 0 Conselho Municipal de Turismo de Parnaíba e o Fundo Municipal de Turismo - FUMTUR. Desse modo, foram observados aspectos, como composição e atribuições dessa instância.

O COMTUR é formado por 11 representantes de órgãos governamentais, entidades da iniciativa privada e terceiro setor tais como: i) Superintendência Municipal de Turismo, ii) Secretaria Municipal de Infraestrutura, iii) Secretaria Municipal de Finanças, iv) Superintendência Municipal de Cultura, v) Superintendência de Planejamento, vi) APADELTA/ICMBIO (Instituto Chico Mendes de Conservação da Biodiversidade), vii) ABAV (Associação Brasileira das Agências de Viagens), viii) Curso de Turismo da Universidade Federal do Piauí, ix) SEBRAE (Serviço Brasileiro de Apoio às Micros e Pequenas Empresas), x) ONG Tartarugas do Delta e xi) ACP (Associação Comercial e Industrial de Parnaíba). Segundo o membro 1 do COMTUR, esse espaço em tese, possibilita a representatividade de um amplo espectro dos atores turísticos locais. Das funções previstas pela prefeitura municipal, observou-se que aquelas que permeiam a população local são: 
Articular-se com instituições de ensino, entidades de classe e da rede de educação profissional, visando estabelecer parcerias que maximizem os investimentos em programas de qualificação profissional e ampliação do mercado de trabalho, promovendo o turismo como fator de inclusão social (Art 7º, inciso X).

Consolidar o apoio à produção local e à comercialização através de ações cooperadas como estratégia de diversificação da oferta turística, incentivando a inserção dos produtos aos destinos e roteiros (Art 7을 inciso XVII);

Receber e analisar denúncias, propostas e sugestões da comunidade e sociedade civil organizada, encaminhando-as ao setor competente da administração pública municipal (Art 7º, inciso XXVI);

Outras organizações, entidades e/ou instituições, inclusive as financeiras, que interagirem com 0 Conselho poderão participar de suas reuniões, se convidadas, sendo-lhes facultado manifestar-se sobre os assuntos abordados, sem, entretanto, ter direito a voto (Art $\left.8^{\circ}\right)$.

Percebe-se, que as funções do COMTUR podem ser classificadas como diretas ou indiretas. Contudo, atingem o público local, tendo em vista que possuem objetivos claros que se repercutem a partir de diferentes finalidades.

A SUPTUR é responsável direta por promover e viabilizar parcerias específicas relacionadas ao desenvolvimento turístico local. As funções da SUPTUR e do Conselho Municipal de Turismo estão distribuídas essencialmente nas seguintes deliberações:

- Criação do Litoral Piauiense Convention \& Visitors Bureau - LPC\&VB no ano de 2015;

- Definição de estratégias para restabelecer a Agência de Desenvolvimento Regional Sustentável (ADRS) ${ }^{2}$;

- Acompanhamento da situação dos voos regulares do município e do Projeto de Urbanização da Orla da Pedra do Sal;

- Iniciativa de criação do Observatório de Turismo em parceria com a Universidade Federal do Piauí;

- Terceirização dos funcionários do Terminal Rodoviário;

- Criação e acompanhamento do Programa Litoral Mais ${ }^{3}$;

- Implantação de Sinalização Turística;

- Criação de três eventos anuais: Réveillon da Feliz Cidade, Parnaíba de Música Independente Brasileira - MPMIB e Festival de Férias.

A SUPTUR tem se engajado desde 2014 para elaborar um Plano Municipal de Turismo para o município. Segundo a Prefeitura Municipal (2014), o primeiro passo dado para essa iniciativa foi a realização da Conferência Municipal de Turismo de Parnaíba, na qual se propôs a 
desenvolver um diálogo com a comunidade local e instituições parceiras, a fim de debater sobre a situação do turismo no município e elencar as estratégias que devem ser tomadas a curto, médio e longo prazo para o desenvolvimento da atividade turística no local. No entanto, é uma etapa de um processo gradativo a ser realizado em função do desenvolvimento da atividade no contexto local que ainda não se efetivou.

Diante do exposto, percebe-se que a população local, mesmo de forma ainda tímida é inserida na concepção das políticas de turismo no âmbito municipal, uma vez que não Ihe são atribuídos maiores poderes e/ou oportunidades e tampouco surge em um documento de grande visibilidade.

Esse aspecto é percebido pela população local, a partir do momento em que sente uma maior necessidade de legislação na área, bem como também desconhece sua existência, elemento que coaduna com o interesse desses agentes em relação à prática da atividade. Conforme pode ser observado a seguir:

\begin{abstract}
"Qualquer que seja a lei afeta a sociedade, independente de qual área, porém é na geração de emprego e renda que o turismo expande seus horizontes e se torna atrativo". No entanto, a atividade precisa de uma lei específica para regulamentar o setor no município. - (Entrevistado 1).

"Aqui em Parnaíba desconheço uma lei específica que afete de forma incisiva a população local, uma vez que é incipiente (para não dizer nula a existência de uma lei na área do turismo a nível local)". - (Entrevistado 2).
\end{abstract}

"A população local parece ser sempre afetada pelo processo de operacionalização da atividade e sempre exige a participação dos moradores enquanto agentes participativos na atividade socioeconômica". Até o momento não conheço uma lei própria do segmento. - (Entrevistado 3).

$\mathrm{Na}$ opinião dos residentes e do membro 2 do COMTUR, a população local é inserida nas leis e/ou deliberações de turismo em Parnaíba como premissa de operacionalização, uma vez que sem este recurso a atividade sequer ganharia notoriedade, não teria aplicabilidade. Em termos legais, se sentem desamparados, porém consideram relevante a contribuição da atividade turística para o município.

Em relação aos aspectos operacionais, os residentes devem ser reconhecidos como sujeitos indispensáveis no processo de planejamento da atividade turística e não como um recurso instrumental como ocorrem em alguns contextos (ALVES et al., 2009). De acordo com o membro 1 do COMTUR, espera-se que esta seja a premissa básica de atuação de um conselho municipal de turismo. Pode-se constatar que as principais intervenções públicas na localidade estão concentradas nas seguintes áreas, conforme opinião dos participantes: 
"Não posso eleger uma das intervenções entre obras, eventos e capacitação, entendo que foi realizada um pouco de tudo e impactaram a população de forma diferenciada". (Entrevistado 4).

"Na minha opinião a natureza dos investimentos no município está concentrada nas obras, tendo no sistema de esgotamento sanitário de Parnaíba um bom resultado, digo porque também ocorreu dentro do prazo estabelecido, e sem dúvida, foi uma intervenção fomentada pelo Ministério do Turismo e sentida pela população". - (Entrevistado 5).

"A capacitação da mão de obra veio junto aos grandes eventos nacionais, como a Copa do Mundo de 2014 e as olimpíadas Rio 2016, posto que tais eventos aludiram a capacitação para uma série de atividades, sobretudo no setor de eventos". - (Entrevistado 6).

Conforme observado nos comentários, a natureza das intervenções turísticas realizadas no município que interferiram diretamente junto à população local, no período de 2010 e 2016 foram desenvolvidas nas áreas de obras, eventos e capacitação profissional. No que se refere aos maiores benefícios das ações junto à população local até o momento, percebeu-se, de acordo com a opinião dos residentes, que:

\footnotetext{
"Não consigo destacar apenas uma das variáveis, uma vez que o turismo promove inserções simultâneas em diversas áreas e setores". - (Entrevistado 7).

"O setor econômico recebe sempre a maior fatia gerada pelo turismo, enquanto a sociedade, a cultura e o meio ambiente são fatores de atração para o turismo, nas quais geralmente recaem os efeitos negativos". (Entrevistado 8).
}

Muitos estudiosos afirmam que o turismo tangencia os diversos aspectos sociais junto ao contexto local, especialmente os relacionados aos fatores econômicos, sociais, culturais e ambientais (CAÑIZARES et al., 2014; CARDONA, 2015; CHEN; CHEN, 2010; DÍAZ; LLURDÉS, 2013; EUSÉBIO; RODRIGUES, 2014; GORICA et al., 2012; LEE, 2013; MAZÓN, 2012; NKEMNGU, 2015; NUNKOO; RAMKISSOON, 2010; SANTOS et al., 2014).

Desse modo, verifica-se que Parnaíba é um destino que além das repercussões e suas particularidades em relação à gestão da atividade, ainda vê na prática turística uma alternativa de melhor aproveitamento dos recursos turísticos existentes e utiliza-se das ferramentas que possui para atrair um número significativo de turistas para a região. No entanto, a prerrogativa para o desenvolvimento da prática não pode estar limitada somente a duas ou três variáveis de planejamento, tendo em vista que a atividade pode entrar em processo de declínio. 
Dada a situação relacionada ao desenvolvimento turístico do município, os membros do COMTUR entendem que deve haver uma postura mais incisiva do Conselho, notadamente sobre a necessidade de sensibilização da população local acerca da relevância da atividade turística, pois para os membros, a falta de continuidade administrativa e de comprometimento de alguns membros mina 0 ambiente de deliberações significativas para 0 desenvolvimento da atividade turística local. Até o momento, entende-se que a potencialidade turística é inversamente proporcional ao avanço político e administrativo da atividade, concentrando-se em questões bem pontuais.

\section{Políticas de turismo em Parnaíba: percepção dos residentes locais}

Serão apresentados os resultados da pesquisa de campo realizada com os residentes dos bairros: Nossa Senhora do Carmo; São Judas Tadeu; Nossa Senhora de Fátima e Centro de Parnaíba em relação à repercussão das intervenções públicas realizadas na localidade, como: PAC, Contratos de Repasse, PRODETUR e PRONATEC.

Para a realização do cálculo do tamanho da amostra, a técnica estatística utilizada foi Amostragem Aleatória Estratificada. Este tipo de plano amostral se caracteriza por dividir a população em partes mais homogêneas comparadas à população em geral. Em seguida foi retirada uma amostra simples das populações para cada um dos bairros, determinando o tamanho da amostra proporcionalmente ao tamanho da população por bairros (BOLFARINE; BUSSAB, 2005).

Para o tamanho da amostra foi atribuído um $\alpha=10 \%$ e margem de erro de 0,10 . Como a proporção era desconhecida foi atribuído um $p=0,5$. Deste modo, a amostra consiste na seguinte proporção:

$$
\begin{aligned}
& \text { Estrato 1: Nossa Senhora do Carmo - } 24 \\
& \text { Estrato 2: Nossa Senhora de Fátima - } 24 \\
& \text { Estrato 3: Centro - } 11 \\
& \text { Estrato 4: São Judas Tadeu- } 22
\end{aligned}
$$

A fim de identificar o tamanho da amostra partiu-se do pressuposto denominado tamanho da amostra com alocação proporcional, sendo utilizada a seguinte fórmula:

$$
\begin{gathered}
n=\frac{\sum_{h=1}^{H} \frac{N_{h}^{2} \cdot p_{h} \cdot \widehat{q}_{h}}{W_{h}}}{\frac{N^{2} E^{2}}{Z_{\alpha / 2}^{2}}+\sum_{h=1}^{H} N_{h} \cdot \widehat{p}_{h} \cdot \widehat{q}_{h}} \\
W_{h}=\frac{N_{h}}{\sum_{k=1}^{H} N_{k}}=\frac{N_{h}}{N}
\end{gathered}
$$


Onde:

$\mathrm{N}$ - tamanho da amostra, neste caso tamanho da população para os bairros estudados;

p - proporção da população para cada um dos bairros;

$q-1-p$; diferença de 1 menos a proporção da população para cada um dos bairros;

w - peso para cada um dos grupos;

$\mathrm{h}$ - cada um dos bairros, neste trabalho foram utilizados 4;

$\mathrm{N}_{\mathrm{k}}$ - População para cada um dos bairros estudados;

E - Erro para cálculo da amostra;

$Z_{\alpha / 2}^{2}$ - Valor da distribuição normal, que considera os dados independentes e identicamente distribuídos, considerando o erro de $10 \%$.

Após calculada o tamanho da amostra, a alocação para cada um dos bairros foi realizada com base no tamanho da população de cada um deles, com a fórmula da alocação proporcional:

$$
n h=\frac{N H}{w h}
$$

Sendo:

nh - tamanho da amostra para cada um dos bairros;

$\mathrm{NH}$ - tamanho total da amostra, no caso 81;

wh - o peso para cada um dos grupos, no caso bairros.

O tamanho da amostra é de 81 pessoas, alocadas em quatro estratos, no qual foi utilizado o software estatístico $R$, para seu cálculo. Entretanto a seleção dos entrevistados foi realizada por amostragem por conveniência.

O perfil dos entrevistados é composto por cinquenta e uma mulheres (63\%); trinta e sete participantes com nível superior incompleto (46\%); trinta e quatro com faixa etária entre 23 à 31 anos de idade (42\%) e quarenta e um com renda que varia de 01 a 02 salários mínimos (51\%).

A respeito do conhecimento de alguma obra realizada no município para o benefício do turismo nos últimos cinco anos, percebeu-se que os entrevistados foram unânimes (100\%), ao reconhecerem a existência de intervenções públicas em Parnaíba.

A literatura destaca o Estado como um objeto de planejamento e gestão (VERGARA; BORTONE, 2012) e que, a partir da administração pública, desenvolve pelo menos três funções básicas: o planejamento, a execução e a supervisão das atividades que executam (ACERENZA, 2002). Alguns autores acrescentam ainda, coordenação, legislação e regulamentação (BENI, 2006; HALL, 2001; TELFER; SHARPLEY, 2008). No entanto, essa realidade não é desenvolvida como se espera em algumas localidades, e esse aspecto se repercute na prática do turismo e na forma como são realizadas as intervenções nos municípios (ALVES; FONSECA; ALVES, 2009). 
Para os entrevistados, as intervenções públicas tiveram diferentes finalidades, das quais foram citadas: a) Ampliação das opções de lazer e entretenimento; b) Diversificação dos espaços coletivos; c) Melhoria da infraestrutura.

Outro ponto levantado na pesquisa se propôs a investigar qual(is) intervenção(ões), no entendimento dos entrevistados, foram efetivadas, sendo apontadas as seguintes aferições: Praças do município; Reabertura do Aeroporto; Pavimentação Asfáltica e Beira Rio, conforme pode ser observado no Gráfico 1.

Gráfico 1: Obras realizadas no município de Parnaíba-PI.

Graphic 1: Works carried out in the municipality of Parnaíba-PI.

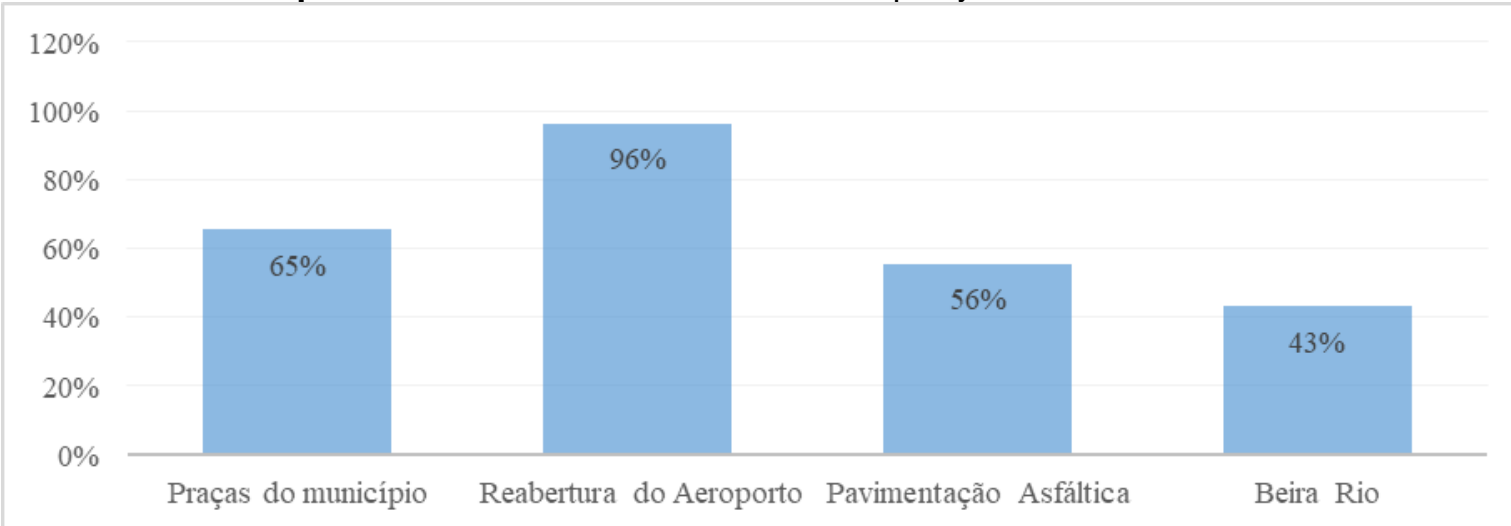

Fonte: Dados da Pesquisa, 2016.

Source: Search Data, 2016.

Em relação à reabertura do Aeroporto Internacional de Parnaíba, denominado Prefeito Dr. João Silva Filho, os recursos foram utilizados para a ampliação e reforço da pista de pouso e decolagem, reforço da pista de táxi, pavimento dos acostamentos, inserção de um sistema de balizamento noturno e sinalização horizontal (INFRAERO, 2011). A intervenção foi realizada pelo PAC, sendo finalizada no ano de 2010 , tendo o valor investido em dezoito milhões de reais e oito centavos $(R \$ 18.000 .000,08)$.

Quanto aos investimentos desenvolvidos nas praças, verificou-se que o volume de investimentos não provém do MTUR, pois são de origem local, derivados do Projeto de Revitalização das Praças de Parnaíba. Segundo informações da Prefeitura, na Praça da Graça foram realizados projetos no âmbito arquitetônico, com a mudança do piso e aspecto paisagístico. $\mathrm{Na}$ Praça Santo Antônio, ocorreu instalações de lixeiras, recuperação de bancos, serviços de jardinagem e instalação de um parquinho para crianças, não sendo revelado o valor desse investimento.

Acerca dos investimentos nas praças, os moradores locais teceram alguns comentários: 
- "Vou à praça pelo menos dois dias na semana me encontrar com amigos".

- "Venho todos os dias vender picolé aqui, porque tem gente agora pra comprar".

- "Fico feliz com as praças organizadas".

•"Agora vejo no que está sendo investido o dinheiro público".

Os sujeitos entrevistados também reforçam no discurso que foram obras necessárias para o contexto local, existe o entendimento de que a gestão municipal deve considerar outros fatores, como saúde, educação, transporte público e mais oportunidade de trabalho para a população local. Aspecto que reforça o pensamento de Mazón (2012), ao considerar que um destino turístico é formado por elementos de caráter físico ou estático, quais sejam: recursos, atrativos turísticos e infraestrutura de apoio.

No que se refere à construção e recuperação de pavimentação asfáltica de ruas e avenidas do município de Parnaíba, percebeu-se que foi uma obra necessária que contribuiu para a melhoria do acesso viário e que repercutiu positivamente junto aos residentes da localidade, conforme pode ser observado: a) "Gostei do que fizeram nas avenidas da cidade"; b) "Ficou muito melhor dirigir em Parnaíba"; c) "Claro que precisava de muito mais, pelo menos as avenidas da cidade estão sendo cuidadas".

As intervenções públicas nas vias do município foram, respectivamente: Pavimentação Poliédrica ${ }^{4}$ de $20.000 \mathrm{~m}^{2}$ e Pavimentação Asfáltica de $12.000 \mathrm{~m}^{2}$; Pavimentação de $24.281 \mathrm{~m}^{2}$ de ruas e avenidas e Recuperação de Pavimento Asfáltico - infraestrutura em municípios turísticos. A partir desta constatação, percebeu-se que a população local fez referência a essa obra por ser uma intervenção com maior frequência entre as demais.

No decorrer das abordagens, percebeu-se ainda que alguns sujeitos da pesquisa mencionaram a execução de uma obra nas imediações da Beira Rio, relevante área turística para a região, na qual há uma concentração acentuada de bares, restaurantes e pizzarias que oferecem pratos típicos da culinária regional. A partir dessas informações, foi realizada uma investigação da realidade, na qual constatou-se que a obra se denomina Boulevard é derivada da modalidade Contrato de Repasse ${ }^{5}$ junto ao MTUR.

Segundo o MTUR (2016), a obra teve um investimento orçamentário no valor de quatrocentos e noventa e três mil e quatrocentos e quarenta e oito reais e oitenta centavos ( $R \$ 493.448,80)$, do qual foi realizada $88,5 \%$ até o mês de março de 2017. A intervenção é parte do Programa de Requalificação e Modernização dos Espaços Urbanos do Ministério do Turismo. O projeto está localizado aonde foi desenvolvido o projeto Calçadão Cultural. Ainda foram realizados os demais investimentos na modalidade Contrato de Repasse, conforme podem ser observados no Quadro 1: 
Quadro 1: Investimentos Contrato de Repasse.

Box 1: Investments Transfer Agreement.

\begin{tabular}{|l|c|c|c|}
\hline \multicolumn{1}{|c|}{ NATUREZA } & ORIGEM & ANO & VALOR \\
\hline Urbanização da orla marítima da pedra do sal & MTUR & 2012 & $\mathrm{R} \$ 4.155 .757,8$ \\
\hline Sinalização Turística & MTUR & 2013 & $\mathrm{R} \$ 550.000$ \\
\hline $\begin{array}{l}\text { Construção e recuperação de pavimentação asfáltica } \\
\text { de ruas e avenidas no município de Parnaíba }\end{array}$ & MTUR & 2013 & $\mathrm{R} \$ 5.080 .000$ \\
\hline TOTAL & & $\mathrm{R} \$ 9.785 .757,80$ \\
\hline
\end{tabular}

Fonte: Ministério do Turismo, 2016

Source: Ministry of Tourism, 2016.

É válido destacar que houveram outros investimentos no âmbito do turismo realizados no município, a exemplo do Sistema de Esgotamento Sanitário, referente aos investimentos do PRODETUR/NE II, mencionado por alguns sujeitos da pesquisa, uma vez que se entende que era considerada uma necessidade básica para a realidade local, pois o município tinha muitos problemas relacionados a este tipo de infraestrutura. Das intervenções realizadas pelo programa na região, este teve o valor mais representativo. $O$ programa ainda realizou outras intervenções no município, nos seguintes componentes: Estudos e Projetos e Saneamento Básico, conforme podem ser observadas no Quadro 2:

Quadro 2: Investimentos do PRODETUR/NE II em Parnaíba.

Box 2: Investments of PRODETUR / NE II in Parnaíba.

\begin{tabular}{|c|c|c|c|}
\hline NATUREZA & ORIGEM & ANO & VALOR \\
\hline $\begin{array}{c}\text { Execução do Projeto de Controle Ambiental das } \\
\text { Dunas da Lagoa do Portinho }\end{array}$ & MTUR & 2010 & $\mathrm{R} \$ 924.965,74$ \\
\hline $\begin{array}{c}\text { Implantação do Sistema de Esgotamento Sanitário- } \\
\text { SES }\end{array}$ & MTUR & 2010 & $\mathrm{R} \$ 12.739 .825,27$ \\
\hline $\begin{array}{c}\text { Elaboração da Avaliação Ambiental Estratégica do } \\
\text { PRODETUR Nacional do Estado do Piauí }\end{array}$ & MTUR & 2010 & $\mathrm{R} \$ 205.584,22$ \\
\hline \multicolumn{2}{|c|}{ TOTAL } & $\mathrm{R} \$ 13.870 .375,23$ \\
\hline
\end{tabular}

Fonte: Adaptado de Governo Federal, 2017 e Milewski, 2012.

Source: Adapted from Federal Government, 2017 and Milewski, 2012.

Em relação à contribuição das obras para o município, observa-se que os dados mais significativos estão associados a geração de renda com trinta e três participantes (41\%) e eventos com vinte e cinco (31\%). Os demais assinalaram ainda, lazer/entretenimento com dezesseis (20\%) e outro com sete $(8 \%)$, destacando a contribuição dos investimentos na infraestrutura do local, conforme pode ser observado no Gráfico 2. 
Gráfico 2: Contribuição das obras para o município.

Graphic 2: Contribution of works to the municipality.

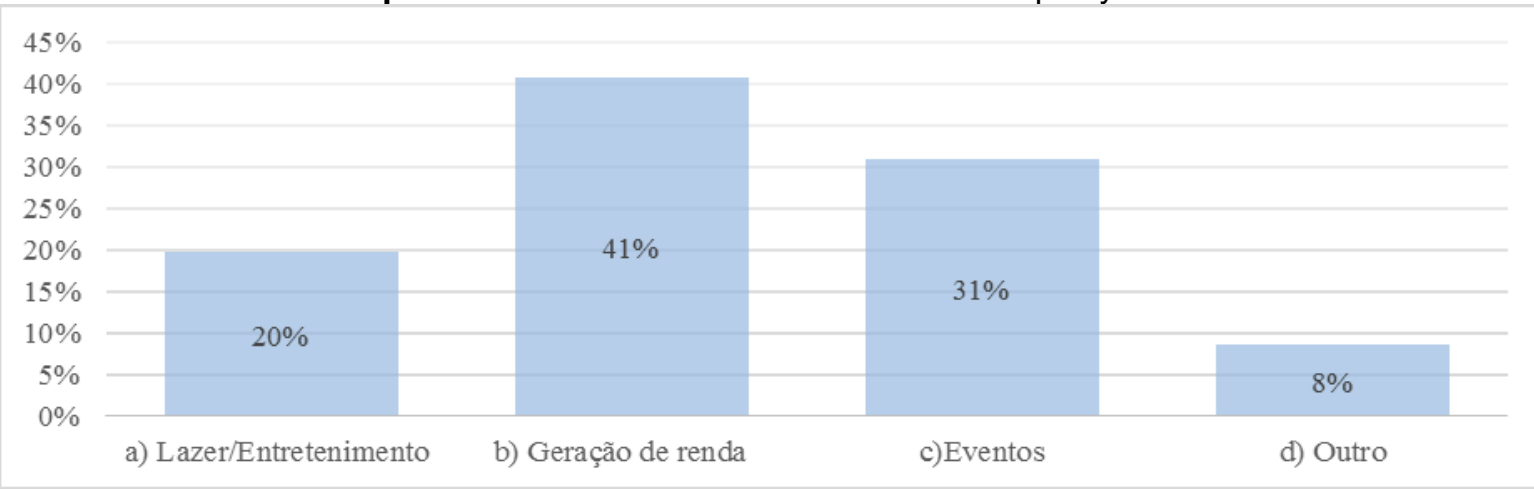

Fonte: Dados da Pesquisa, 2016.

Source: Search Data, 2016.

Segundo o Plano Estratégico de Desenvolvimento do Turismo Regional da Rota das Emoções (2014, p.143), "existem aproximadamente 7000 empregos diretos nos estabelecimentos de turismo ao longo da Rota das Emoções, sendo que $35 \%$ desses postos de trabalho são temporários (contratos por tempo determinado, freelancers e diaristas)". Essa constatação pode favorecer o aumento da sensação de bem-estar em relação à geração de emprego e renda, porém também interfere diretamente na operacionalização de ações de capacitação da mão-de-obra e no nível dos serviços turísticos, sobretudo nos setores de hospedagem e alimentação.

Foi constatado que quarenta e dois participantes (52\%), foram favoráveis em relação às obras realizadas na localidade, isto é, consideram que as ações foram oportunas para o contexto, mas entendem que é um componente entre os demais necessários ao desenvolvimento do turismo local.

Ainda, foi verificado que onze participantes (14\%) se sentem totalmente insatisfeitos com as intervenções públicas desenvolvidas na localidade, uma vez que as ações não atenderam às expectativas dessa parcela, tendo em vista que a prejudicou em relação a alguns aspectos particulares, a exemplo da morosidade nas ações desenvolvidas e o custo social e econômico revertido ao público diretamente afetado.

Catorze (17\%) estão insatisfeitos em parte com os investimentos públicos, tendo em vista que existem outras questões a serem tratadas no município, sendo que na percepção destes, existe a necessidade de intervir em áreas também consideradas turísticas para o município, como o Porto das Barcas.

Outro aspecto a ser considerado na análise, é que doze participantes (15\%) estão satisfeitos parcialmente em relação ao que foi efetivado na localidade, isto é, reconhecem que houve investimentos, no entanto, sempre há o que melhorar no município. Por fim, percebe-se que dois $(2 \%)$, sentemse totalmente satisfeitos com os investimentos realizados em Parnaíba. A atividade turística é considerada um fenômeno social significativo 
(ACERENZA, 2002; VELASCO, 2011), uma vez que sua repercussão junto à população local se desenvolve, a partir de diferentes tipos e graus de satisfação, conforme se observa no Gráfico 3:

Gráfico 3: Percepção em relação às obras voltadas ao incremento do turismo.

Graphic 3: Perception of works aimed at increasing tourism.

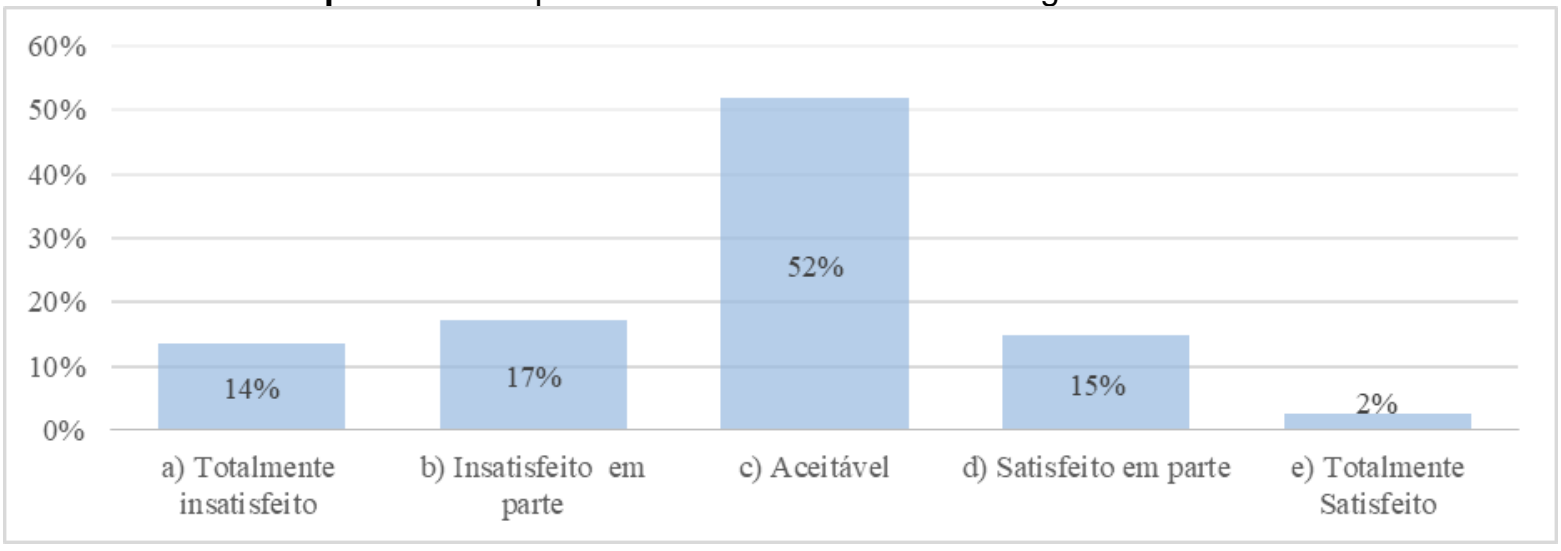

Fonte: Dados da Pesquisa, 2016

Source: Search Data, 2016.

A respeito do público favorecido com a realização das obras, a maioria dos entrevistados, isto é, cinquenta participantes (62\%), entende que as obras beneficiaram a população local, uma vez que os investimentos contribuíram para melhorar a infraestrutura da cidade e a geração de emprego e renda. Dos demais abordados, trinta e um (38\%), afirmaram que os investimentos favoreceram os turistas, tendo em vista que beneficiaram especialmente os espaços turísticos do município.

Sobre a participação em cursos de capacitação profissional voltado para o turismo, a maioria dos participantes, cinquenta e quatro entrevistados (67\%), já se envolveu em algum curso, todavia, vinte e sete (33\%) nunca o realizou, apresentando em sua maioria as seguintes justificativas: falta de tempo, cursos desinteressantes e problemas na divulgação.

Dos cursos realizados pelos entrevistados, foi constatado que dezesseis participantes (30\%), são oriundos dos cursos do Serviço Social da Indústria- Sesi/ Serviço Nacional de Aprendizagem Industrial- Senai, catorze (26\%), do Serviço Social do Comércio- Sesc/ Serviço Nacional de Aprendizagem Comercial- Senac, oito (19\%), dos cursos oferecidos pelo Estado, dez (15\%), dos cursos disponibilizados por outra instituição, a exemplo do Instituto Federal do Piauí- IFPI e Serviço de Apoio às Micros e Pequenas Empresas do Piauí- SEBRAE e seis (10\%), correspondem aos cursos oferecidos pela Prefeitura, conforme pode ser observado no Gráfico 4: 
Gráfico 4: Oferta dos cursos em Parnaíba-PI.

Graphic 4: Course offer in Parnaíba-PI.

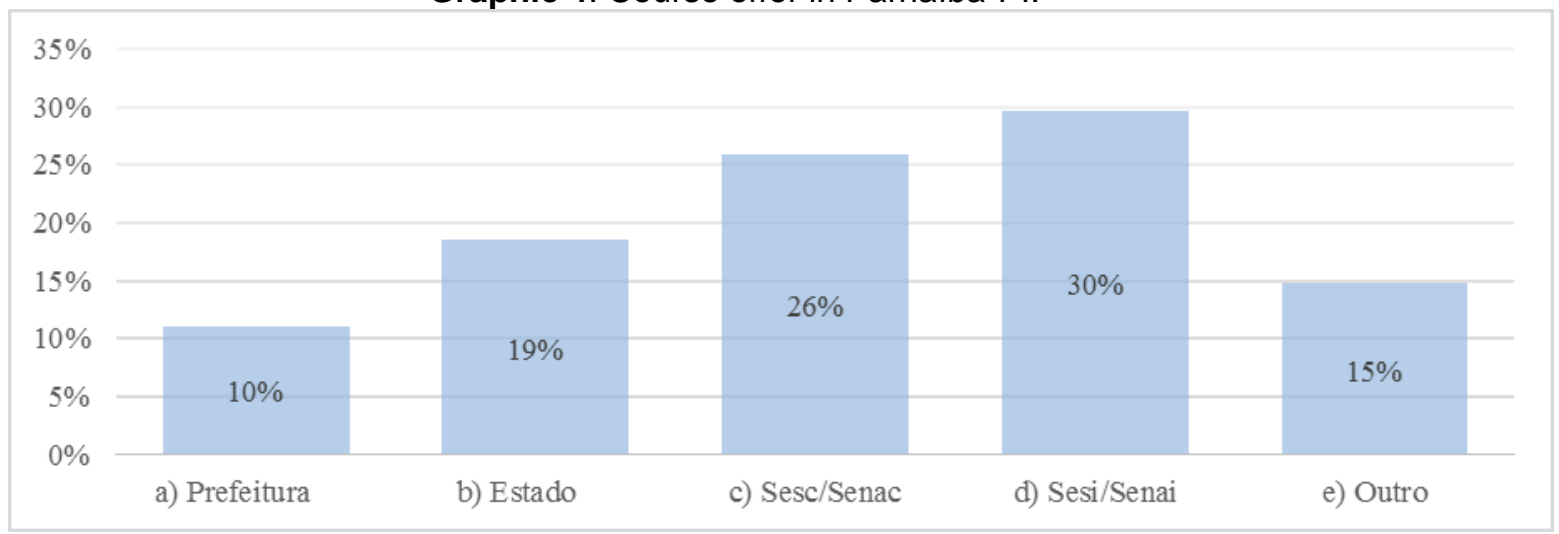

Fonte: Dados da Pesquisa, 2016.

Source: Search Data, 2016.

A pesquisa permitiu constatar que aqueles participantes inseridos nos sessenta e sete por cento (67\%) que já realizou algum curso de capacitação profissional voltado para o turismo, têm interesse de participar de cursos de capacitação profissional, dos quais, vinte e três (43\%), indicaram o curso de idiomas, dezesseis (30\%), optaram pelo curso de camareira, oito (15\%), pelo curso de garçom e sete (12\%) outro.

Para os sujeitos da pesquisa inseridos na categoria outro, as inferências apresentadas foram, em sua maioria: a) Organizador de eventos; b) Agente de viagem; c) Recreador; d) Gastronomia; e) Cerimonialista.

De acordo com os sujeitos da pesquisa, estes cursos são necessários no município, tendo em vista que há mercado para as ocupações. Foi observado que esse grupo entende que a diversidade de cursos profissionalizantes tende a agregar maior valor à atividade turística, tendo em vista que aumenta o número de serviços relacionados à sua prática, isto é, torna-se uma ferramenta estratégica para ambas as partes envolvidas no seu exercício e possivelmente possam contribuir para a efetivação de outro nicho de mercado para o município.

Segundo o Plano Estratégico de Desenvolvimento do Turismo Regional da Rota das Emoções (2014), o município necessita realizar cursos de capacitação nos níveis operacional e gerencial, dentre eles: auxiliar de cozinha, camareira, recepcionista, garçom, condutor de turismo, inglês instrumental para condutores de turismo, inglês instrumental para recepcionista, inglês instrumental para garçons, controladoria, gestão de pessoas, sistema de qualidade e inovação/ empreendedorismo, elementos que corroboram com o resultado obtido.

Os participantes da pesquisa também avaliaram a contribuição do turismo para o município de Parnaíba, atribuindo-Ihe notas que variam entre 1 (totalmente insatisfeito) a 5 (totalmente satisfeito) em relação ao serviços urbanos a partir das seguintes categorias: mais oportunidades de emprego e renda, melhoria na infraestrutura da cidade, geração de fluxo turístico, qualificação profissional, aumento do índice de violência, poluição para a 
cidade, aumento dos preços e das refeições, imóveis e etc., conflitos com turistas (barulho, idioma, entre outros).

Ao que se refere à nota 1, observa-se que a maioria dos entrevistados estão totalmente insatisfeitos com o aumento da violência, sendo que do total de participantes percebe-se que quarenta e cinco (56\%), apontaram para tal questão. Ao se observar a nota 2, tem-se presente o aumento dos preços das refeições e da especulação imobiliária com quarenta e um (51\%), ou seja, os participantes se encontram insatisfeitos com essa categoria.

$\mathrm{Na}$ nota 3, a qualificação profissional, apresentou quarenta e dois entrevistados (52\%), acompanhado de Conflitos com os turistas, com trinta e sete $(47 \%)$ e Poluição para a cidade com trinta e seis (43\%). Nessa categoria, os entrevistados encontram-se em uma situação aceitável em relação à contribuição do turismo para a localidade, isto é, estão situados em um nível intermediário.

Foi constatado que na nota 4 a categoria mais expressiva foi melhoria na infraestrutura da cidade, com quarenta e cinco participantes (56\%) e oportunidade de emprego e renda com quarenta e um (51\%), aspecto tido como satisfatório em parte, para os entrevistados da pesquisa, pois, os residentes reconhecem que foi considerável a contribuição do turismo.

Por fim, a nota 5 , categoria predominante em relação às demais foi geração de fluxo turístico (mais turistas), com trinta e nove participantes (48\%) das avaliações realizadas, tendo em vista que os residentes encontram-se totalmente satisfeitos no que se refere ao fluxo de turistas para o município, conforme pode ser verificado no quadro 3, em relação ao grau de contribuição do turismo para o município de Parnaíba. Observa-se que os residentes entendem que o turismo interfere diretamente na localidade, causando tanto benefícios, quanto malefícios a ele associados. A dinâmica da atividade está relacionada a um conjunto de fatores interdependentes e complementares, intervindo, portanto, no desenvolvimento do destino.

Quadro 3: Contribuição do turismo para o município de Parnaíba

Box 3: Contribution of tourism to the municipality of Parnaíba

\begin{tabular}{|l|c|c|c|c|c|c|}
\hline \multicolumn{2}{|c|}{ CATEGORIAS } & \multicolumn{5}{c|}{ NOTAS } \\
\cline { 2 - 6 } & $\mathbf{1}$ & $\mathbf{2}$ & $\mathbf{3}$ & $\mathbf{4}$ & $\mathbf{5}$ & TOTAL \\
\hline Mais oportunidades de emprego e renda & $6 \%$ & $14 \%$ & $20 \%$ & $51 \%$ & $9 \%$ & $100 \%$ \\
\hline Melhoria na infraestrutura da cidade & $7 \%$ & $12 \%$ & $14 \%$ & $56 \%$ & $11 \%$ & $100 \%$ \\
\hline Geração de fluxo turístico (mais turistas) & $3 \%$ & $9 \%$ & $16 \%$ & $24 \%$ & $48 \%$ & $100 \%$ \\
\hline Qualificação profissional & $11 \%$ & $15 \%$ & $52 \%$ & $15 \%$ & $7 \%$ & $100 \%$ \\
\hline Aumento do índice de violência & $56 \%$ & $24 \%$ & $13 \%$ & $6 \%$ & $1 \%$ & $100 \%$ \\
\hline Poluição para cidade & $6 \%$ & $25 \%$ & $43 \%$ & $22 \%$ & $4 \%$ & $100 \%$ \\
\hline $\begin{array}{l}\text { Aumento dos preços das refeições, imóveis, } \\
\text { entre outros. }\end{array}$ & $23 \%$ & $51 \%$ & $15 \%$ & $9 \%$ & $2 \%$ & $100 \%$ \\
\hline Conflitos com turistas (Barulho, idioma, etc) & $4 \%$ & $16 \%$ & $47 \%$ & $19 \%$ & $14 \%$ & $100 \%$ \\
\hline
\end{tabular}

Fonte: Dados da pesquisa, 2016.

Source: Search Data, 2016. 
Dos investimentos mencionados no decorrer dos resultados, como PAC, Contratos de Repasse, PRODETUR e PRONATEC, constatou-se que a população foi consultada a partir de reuniões e audiências. Contudo, é preciso considerar que as intervenções possuem naturezas diferenciadas que, consequentemente se projetaram de forma proporcional a esta característica, isto é, o público pesquisado foi aquele diretamente envolvido/afetado pela realização das intervenções públicas, sendo, portanto, limitado ao tipo e amplitude do contexto populacional mais geral.

\section{Considerações Finais}

Reconhecemos que os resultados obtidos apresentaram aspectos relevantes. Nesse sentido, torna-se indispensável que a gestão pública local atue de forma estratégica, isto é, utilize os recursos e equipamentos disponíveis no destino, bem como reconheça a necessidade de transpor os desafios subjacentes ao contexto. Essa é uma das maneiras de intervir positivamente junto aos autóctones e beneficiá-los sobremaneira.

Constatou-se que a característica econômica é predominante no discurso oficial e influencia as demais. Atribuição reconhecida pelos participantes como um recurso relevante junto a receptividade da atividade. Entretanto, se percebe que esse cenário poderia ser melhor desenvolvido, a partir do momento que a população seja habilitada para avaliar a atuação e prestação do serviço público, tendo em vista que a esfera local tem maior sensibilidade para reagir a condicionantes específicas.

Não é possível afirmar que a população local se insere efetivamente nas ações públicas específicas de turismo em Parnaíba, porque é necessário haver um ciclo entre a concepção e implementação dessas em todos os níveis de planejamento. Entende-se que a predominância da concepção das ações públicas específicas de turismo ao que se refere à inserção da população, continua sendo operacional. Entretanto, é crucial que a atividade contribua para o desenvolvimento humano, atribuindo-Ihe uma melhoria na qualidade de vida.

Tampouco podemos afirmar que há compatibilidade entre o discurso oficial e a prática, sobretudo em relação a estrutura da gestão local que é diminuta e impede que haja uma verdadeira compatibilização do discurso e da prática. Entretanto, não se trata apenas do valor conjuntural, mas da forma em que são tomadas as decisões, das pautas priorizadas, do nível de cooperação regional do destino (visibilidade), bem como dos recursos financeiros liberados para sua utilização.

Após análise dos principais documentos divulgados pelo MTUR, percebe-se que a relevância atribuída à população local no contexto das políticas públicas definidas para o turismo brasileiro ao longo dos anos, não sofreu mudanças significativas, surgem no discurso oficial dando ênfase ao papel dos residentes e sua complementaridade na atividade turística, sendo utilizado como um importante recurso no planejamento, desenvolvimento e avaliação dos impactos gerados pela atividade. 
Conforme observado na análise dos dados coletados, houve no município um aumento dos índices de violência e dos preços (refeições, imóveis, entre outros), aspectos estes que tendem a serem estimulados a partir dos investimentos no setor turístico em destinos com demanda real e potencial, enquadrando-se na situação da geração de aspectos negativos.

O estudo também aferiu que a esfera pública federal foi a mais atuante, pois interviu decisivamente na realização das ações desenvolvidas na localidade, porém esse cenário é visto como um fator de inquietude no que se refere ao processo de planejamento e gestão do turismo, tendo em vista que provoca uma sobreposição de funções em relação aos agentes públicos responsáveis por desenvolver a atividade, ou seja, demonstra uma relação de dependência entre as esferas competentes e a carência de estrutura física, profissional, bem como de recursos financeiros. Nesse contexto, entende-se que é preciso uma maior articulação do âmbito estadual e municipal para o benefício da atividade no município de Parnaíba-PI.

Quanto às principais ações que promoveram a expansão da atividade turística no município de Parnaíba/PI tais como: PAC, Contratos de Repasse, PRODETUR, PRONATEC, Rota das Emoções e demais deliberações a nível municipal, entende-se que em conjunto auxiliaram a execução de diferentes ações na localidade que se repercutiram junto à população local. Desse modo, o turismo quando bem planejado pode favorecer a expansão de uma prática mais inclusiva, na qual os agentes sociais participam do modelo desenvolvido. Uma população com maior inserção no processo decisório tem maior probabilidade de tomar decisões mais responsáveis.

\section{Referências}

ACERENZA, M.A. Administração do Turismo. Bauru, SP: Edusc., 2002.

AIRES, J.D.; PEQUENO, E.A.; FORTES, L. (2010). A Relação Entre Turistas Estrangeiros e Residentes: O Caso de Ponta Negra-Natal/RN. Revista Hospitalidade, v.7, n.2, p.38-51, 2010.

ALVES, K.M.S., FONSECA, M.A.P., ALVES, A.E.L. O papel do residente na produção do espaço turístico em Natal. Cultur: Revista de Cultura E Turismo, v.3. n.3, p.104-121, 2009.

ANDERECK, K.L.; NYAUPANE, G.P. Exploring the Nature of Tourism and Quality of Life Perceptions among Residents. Journal of Travel Research, v.50, n.3, p.248-260, 2011.

APPOLINÁRIO, F. Dicionário de metodologia científica: Um guia para a produção do conhecimento científico. São Paulo: Atlas, 2004.

ASSANTE, L.M.; WEN, H.I.; LOTTIG, K. An empirical assessment of residents" attitudes for sustainable tourism development: a case study of O"ahu, Hawai'i. Journal of Sustainability and Green Business, v.1, p.1-27, 2012.

BENI, M.C. Política e planejamento de turismo no Brasil. São Paulo: Aleph, 2006. 
BOLFARINE, H.; BUSSAB, W. Elementos de amostragem. São Paulo: Edgard Blücher, 2005.

BRASIL. Embratur 40 Anos. Brasília, 2006.

BRASIL. Programa de Regionalização do Turismo: Diretrizes. Brasília, 2013.

BRASIL. Plano Estratégico de Desenvolvimento do Turismo Regional da Rota das Emoções: Produto V - Entrega de resultados. Brasília, 2014.

BRASIL. MINISTÉRIO DO TURISMO. Contrato de repasse, 2016. Disponível em: <http://repasse.turismo.gov.br/>, acessado em 18 de dezembro de 2016.

CAÑIZARES, S.; TABALES, J.; GARCÍA, F. Local residents' attitudes towards the impact of tourism development in Cape Verde. Tourism \& Management Studies, v.10, n.1, p.87-96, 2014.

CARDONA, J. Efecto de la economía y el entorno en los residentes. Pasos: Revista de Turismo Y Patrimonio Cultural, v.13, n.6, p.1371-1386, 2015.

CARNEIRO, M.J.; EUSÉBIO, C. Host-tourist interaction and impact of tourism on residents' Quality of Life. Tourism \& Management Studies, v.11, n.1, p.25-34, 2015.

CARVALHO, K.D.; GUZMÁN, S.J.M. El turismo en la dinámica territoria. ¿ Lógica global, desarrollo local? Centro de Investigaciones $\mathbf{Y}$ Estudios $\mathbf{Y}$ Perspectivas En Turismo, v.20, n.2, p.441-461, 2011.

CARVALHO, S. A Percepção do Turismo por Parte da Comunidade Local e dos Turistas no Município de Cajueiro da Praia-PI. Turismo Em Análise, v.21, n.3, p.470-493, 2010.

CHEN, C.-F.; CHEN, P.C. Resident Attitudes toward Heritage Tourism Development. Tourism Geographies, v.12, n.4, p.525-545, 2010.

DALL'AGNOL, S. Impactos Do Turismo X Comunidade Local. Anais Do VII Seminário de Pesquisa Em Turismo Do Mercosul, p.1-15, 2012.

DIAS, R. Introdução ao Turismo. São Paulo: Atlas, 2005.

DÍAZ, I.S.; LLURDÉS, J.C.C. Reflexiones sobre el turismo de proximidad como una estrategia para el desarrollo local. Cuadernos de Turismo, v.32, p.65-88, 2013.

ENDRES, A.V. As políticas de turismo e os novos arranjos na Paraíba/Brasil. (Tese de Doutorado). Universidade Federal de Santa Catarina, 2012.

EUSÉBIO, C.; RODRIGUES, S. O desenvolvimento do turismo em destinos rurais : Perceções dos impactes, interação e atitudes dos residentes. Turismo \& Desenvolvimento,v.21/22, p.423-424, 2014.

FRATUCCI, A.C. A dimensão Espacial nas políticas públicas brasileiras de turismo: as possibilidades das redes regionais de turismo. (Tese de Doutorado). Universidade Federal Fluminense, 2008.

FREDLINE, L.; DEERY, M.; JAGO, L. A Longitudinal study of the impacts of an annual event on local residents. Tourism Planning \& Development, v.10, n.4, p.416-432, 2013. 
FAZITO, M.; RODRIGUES, B.; NASCIMENTO, E.; PENA, L.C S. O papel do turismo no desenvolvimento humano. Paper do NAEA 372, Agosto de 2017.

GOELDNER, C.; RITCHIE, J.R.B.; MCINTOSH, R. Políticas de Turismo: estrutura, políticas e processos. In Turismo: princípios, práticas e filosofias. Porto Alegre: Booknman, 2002.

GOHN, M.G. Empoderamento e participação da comunidade em políticas sociais. Saúde E Sociedade, v.13, n.2, p.20-31, 2004.

GORICA, K., KRIPA, D.; ZENELAJ, E. The Role of Local Government in Sustainable Development. Acta Universitatis Danubius, v.8, n.2, p.139-155, 2012.

GURSOY, D.; KENDALL, K.W. Hosting mega events. Modeling Locals' Support. Annals of Tourism Research, v.33, n.3, p.603-623, 2006.

HALL, C.M. Planejamento turístico: política, processos e relacionamentos. São Paulo: Contexto, 2001.

INFRAERO. Informações sobre o Aeroporto Internacional de Parnaíba Prefeito Dr. João Silva Filho. 2011. Disponível em <http://www4.infraero. gov.br/aeroportos/aeroporto-internacional-de-parnaiba-prefeito-dr-joao-silvafilho/>. Acesso em Novembro de 2016.

LEE, T.H. Influence analysis of community resident support for sustainable tourism development. Tourism Management, v.34, p.37-46, 2013.

MAZÓN, A.I. Analisis relacional de sistemas turisticos. Un marco de trabajo alternativo en el proceso de planificacion turistica. Tourism \& Management Studies, v.8, p.1646-2408, 2012.

MCDOWALL, S.; CHOI, Y. Thailand's Destination Image through the Eyes of Its Citizens. International Journal of Hospitality \& Tourism Administration, v. 11, n.3, p.255-274, 2010.

MENG, F.; Li, X.; UYSAL, M. Tourism Development and Regional Quality of Life: The Case of China. Journal of China Tourism Research, v.6, n.2, p.164-182, 2010.

NKEMNGU, A.P. Quality of life and tourism impacts: a community perspective. African Journal of Hospitality, Tourism and Leid, v.4, n.1, p.113, 2015.

NUNKOO, R.; RAMKISSOON, H. Residents' Satisfaction With Community Attributes and Support for Tourism. Journal of Hospitality \& Tourism Research, v.35, n.2, p.171-190, 2010.

OLIVEIRA, A.C. A atividade turística e seus efeitos à população local: um paradoxo. Caderno Virtual de Turismo, v.5, n.2, p.73-87, 2005.

PIMENTEL, M.P.C.; PIMENTEL, T.D. A trajetória das políticas públicas de turismo brasileiras 1930-2010. Anais do XXXV Encontro Da ANPAD, p.1-17, 2011. 
RODRIGUES, A.P.; VIEIRA, I.; MARQUES, C.P.; TEIXEIRA, M.S. Apoio da comunidade residente ao desenvolvimento turístico sustentável: um modelo de equações estruturais aplicado a uma cidade histórica do Norte de Portugal. Tourism \& Management Studies, v.10, n.2, p.17-25, 2014.

SANTOS, M.M.; FERREIRA, A.M.; COSTA, C. Influential factors in the competitiveness of mature tourism destinations. Tourism \& Management Studies, v.10, n.1, p.73-81, 2014.

TELFER, D.J.; SHARPLEY, R. Tourism and Development in the Developing World. London: Routledge, 2008.

VELASCO, M. La Política Turística. Una Arena De Acción Autónoma. Cuadernos de Turismo, v.27, p.953-969, 2011.

VELASCO, M.; SANTOS, R. La relación entre acción pública y turismo desde diversas perspectivas: ideas, actores e instituciones. Pasos: Revista de Turismo Y Patrimonio Cultural, v.14, n.3, p.573-751, 2016.

VERGARA, E.M.; BORTONE, N.A.B. El Municipio: destino local. Tres dimensiones y una función rectora. Provincia, v.27, p.11-42, 2012.

\section{Notas:}

${ }^{1}$ É o resultado de um processo de planejamento compartilhado em turismo, iniciado em 2003 com enfoque regional, e regulamentado pela Lei Geral do Turismo 11.771, de 2008. Segundo o Plano Nacional de Turismo: o turismo fazendo muito mais pelo Brasil 2013-2016, (2013a) consiste em desenvolver a gestão compartilhada, a partir dos seguintes conceitos: participação, democratização, consensos e acordos entre entes institucionais, econômicos e sociedade civil organizada.

${ }^{2}$ Criada com a finalidade de promover o desenvolvimento integral da região turística dos municípios integrantes da Rota das Emoções, em que abrange 14 municípios dos três estados componentes. Tendo como municípios polos as cidades de Parnaíba (Delta do Parnaíba - Estado do Piauí), Jijoca de Jericoacoara (Jericoacoara - Estado do Ceará) e Barreirinhas (Lenções Maranhenses - Estado do Maranhão) (Superintendência de Turismo de Parnaíba, 2016).

${ }^{3}$ De acordo com informações da Superintendência de Turismo, o Programa Litoral Mais tem o objetivo de qualificar os profissionais do Trade Turístico de Parnaíba, com enfoque na qualidade da oferta dos serviços. No primeiro ano de execução, foram ofertados 07 cursos voltados para o aperfeiçoamento para mais de 150 pessoas, de aproximadamente 24 empresas participantes, a saber: Garçom básico; Relações interpessoais; Gerenciamento de pequenos negócios; WhatsApp Marketing para o Turismo; Marketing digital; Inglês aplicado a serviços turísticos; Oficina de Liderança; Jogos e vivências.

${ }^{4}$ De acordo com Araújo (2004), o termo se refere à colocação de pedras de forma regular ou não em um colchão de areia compactada ou pó de minério, sendo necessário, após a ação, o preenchimento dos vazios com areia e/ou cimento com cal.

${ }^{5}$ Segundo o Governo Federal (2014, p. 2), Contrato de repasse é semelhante ao convênio em relação aos seus fins, porém se diferencia pela intermediação de uma instituição ou agente financeiro público federal, que representa a União na execução e fiscalização da transferência. Salvo se a concedente tenha estrutura para 
acompanhar a execução do convênio, a legislação define contrato de repasse para execução de objeto que preveja a realização de obra (preferencialmente).

\section{Agradecimentos:}

Esta pesquisa teve o apoio da CAPES (Coordenação de Aperfeiçoamento de Pessoal de Nível Superior).

Andreia Magalhães da Rocha: Universidade Estadual do Piauí, Teresina, PI, Brasil.

E-mail: andreiamdr@hotmail.com

Link para o currículo Lattes: http://lattes.cnpq.br/7107853585540338

Wilker Ricardo de Mendonça Nóbrega: Universidade Federal do Rio Grande do Norte, Natal, RN, Brasil.

E-mail: wilkernobrega@yahoo.com.br

Link para o currículo Lattes: http://lattes.cnpq.br/0025142529544906

Mozart Fazito Rezende Filho: Universidade Federal do Rio Grande do Norte, Natal, RN, Brasil.

E-mail:mozart.fazito@gmail.com

Link para o currículo Lattes: http://lattes.cnpq.br/1500119299281914

Data de submissão: 03 de setembro de 2018

Data de recebimento de correções: 31 de outubro de 2018

Data do aceite: 31 de outubro de 2018

Avaliado anonimamente 